\title{
Vantagens e desvantagens do pregão na gestão de compras no setor público: o caso da Funasa - PB
}

\author{
Jacqueline Nunes; Rosivaldo de Lima Lucena e \\ Orlando Gomes da Silva
}

\section{Introdução}

Para qualquer organização, o setor de compras se constitui como um dos segmentos principais para o alcance dos objetivos a serem atingidos. É por meio de uma aquisição de bens e serviços eficiente que uma organização conseguirá atingir seus fins com menos dispêndio de recursos financeiros, tendo por outro lado a satisfação dos seus stakeholders.

O sistema de compras apresenta muitas diferenças quando se compara o setor público às empresas privadas. Em um sistema de mercado, dada a competição entre as firmas, as organizações privadas precisam de um setor de compras eficiente para o cumprimento da meta de maximização dos lucros. Para o alcance dessa meta, são lançadas estratégias que entrelaçam parcerias, fidelização de clientes e relacionamentos de longo prazo a fim de se obter o crescimento constante dos lucros.

Em organizações públicas, o foco é a transparência das relações e o emprego dos recursos para a satisfação da sociedade. Assim, percebe-se que na governabilidade do País deverão ser preservados valores que garantam a eficiência 
e a eficácia na utilização dos bens públicos da sociedade. Para isso, a administração pública vê-se obrigada a utilizar-se de um alto grau de formalismo nas suas relações para aquisições de bens e contratações de serviços.

Diante da necessidade por envolvimento abrangente com todos os aspectos relevantes do nosso País, a compreensão das compras realizadas por órgãos do governo se revela de grande importância para os cidadãos brasileiros. Em geral, tais aquisições são as concretizações de planejamentos anuais que visam à satisfação das necessidades da sociedade brasileira.

Com a finalidade de regulamentar o assunto, a Constituição Federal de 1988, em seu artigo 37, inciso XXI, estabelece que a administração pública direta e indireta de qualquer dos poderes da União, dos estados e dos municípios deverá adquirir bens e serviços mediante processo de licitação pública que assegure igualdade de condições a todos os concorrentes. Assim, a administração pública busca o menor custo e o maior benefício por meio da proposta mais vantajosa, apresentada por procedimentos estabelecidos na licitação para o contrato de seu interesse.

Para aquisição de bens e serviços comuns, a União, os estados, o Distrito Federal e os municípios utilizam-se do pregão, que é uma modalidade de licitação válida para quaisquer limites de valor em que a disputa é feita por meio de propostas e lances em sessão pública. O pregão eletrônico, por sua vez, possui as mesmas premissas da modalidade pregão (presencial), deste diferenciando-se por utilizar recursos de tecnologia da informação. Dessa forma, como objetivo, este artigo se propôs a avaliar quais as vantagens e desvantagens do pregão eletrônico em relação ao pregão presencial para aquisição de bens/serviços na gestão pública de saúde. Para isso, foi estudado o caso da Fundação Nacional de Saúde da Paraíba (FUNASA/PB). A Fundação, órgão executivo do Ministério da Saúde, é uma das instituições do governo federal responsável em promover a inclusão social por meio de ações de saneamento, sendo também responsável pela promoção e proteção à saúde dos povos indígenas.

$\mathrm{O}$ artigo está dividido em oito seções além desta introdução. Na seção 2, A função compras e o instrumento licitação, descrevem-se os principais pontos referentes ao processo de compras via licitação no setor público; na seção 3, O pregão, são destacadas as características da modalidade de licitação pregão, com ênfase nos principais pontos da prática de pregão presencial; na seção 4, Opregão eletrônico, destaca-se o conteúdo mais relevante da prática do pregão eletrônico; na seção 5, são apresentados as características do pregão na FUNASA/PB bem como a análise e interpretação dos resultados da pesquisa; na seção 6, é feita uma comparação entre os métodos de compra: pregão presencial e eletrônico; na seção 7, destacase a reflexão resultante da comparação entre o pregão presencial e o eletrônico. Finalmente, na última seção, são feitas as considerações finais quanto à pesquisa e particularmente à parte divulgada nesse artigo.

\section{A função compras no setor público e o instrumento licitação}

"A função compras é um seguimento essencial do Departamento de Materiais ou Suprimento, que tem por finalidade suprir as necessidades de materiais ou serviços.'(DIAs, 1995, p. 259). Dessa forma, sua atividade consiste no suprimento de bens ou serviços necessários às atividades da organização por meio do planejamento quantitativo, 
satisfazendo-as no momento correto e armazenando-as de maneira adequada.

"As compras, como uma função administrativa, têm a responsabilidade de participar do planejamento e das previsões de sua empresa". (Heinritz; Farrell, 1972, p.252). Assim, o bom planejamento, o controle e a execução das compras para uma organização são indispensáveis ao desenvolvimento das atividades que a compõem, pois mantêm os custos conforme o previsto. Nesse processo, o instrumento licitação é obrigatório para a organização pública, salvo disposições expressas em lei.

A licitação é substanciada por procedimentos administrativos que se relacionam entre o público e os interessados por meio de condições anteriormente acordadas, dentre as quais será selecionada a mais conveniente para a celebração de contrato. (Di Pietro, 2004).

A Lei no 8.666/1993 obriga a aplicação de licitação para contratos de obras, serviços (inclusive de publicidade), compras, alienações, concessões, permissões e locações da administração pública quando contratados com terceiros, ressalvados casos previstos na lei. (art. $2^{\circ}$ ). Já as empresas estatais que possuem personalidade jurídica de direito privado ${ }^{1}$ possuem regulamentos próprios, mas ficam sujeitas às disposições gerais da lei de licitações. (Art. 119). Assim, segundo Meirelles, "justifica-se essa diversidade de tratamento porque as pessoas jurídicas de direito público estão submetidas a normas de operatividade mais rígidas que as pessoas jurídicas de direito privado, que colaboram com o poder público" (2003, p. 269). Temse, ainda, o Decreto $n^{\circ} 5.504 / 2005$, que prevê a obrigatoriedade da realização de licitação pública para entidades não integrantes da administração pública, inclusive as OS e as OSCIP ${ }^{2}$, quando envolvam recursos públicos diretamente repassados pela União. Neste caso, para bens e serviços comuns, é obrigatória a modalidade pregão, sendo preferencial sua forma eletrônica. (Decreto $\mathrm{n}^{\circ} 5.504 / 05$, art $\left.1^{\circ}, \int 1^{\circ}\right)$.

De acordo com a Lei no 8.666/1993, artigo 22, existem cinco modalidades clássicas de licitação: concorrência, tomada de preços, convite, concurso e leilão. A figura 1 apresenta cada uma delas com suas respectivas características.

"Na governabilidade do País deverão ser preservados valores que garantam a eficiência e a eficácia na utilização dos bens públicos da sociedade”.

Segundo GUSMÃO (2004), as modalidades de licitação possuem características próprias que as distinguem umas das outras, sendo cada qual apropriada a determinados tipos de contratação. Analisado o objeto de contratação, seguirá a escolha da modalidade mais apropriada para a efetiva contratação de acordo com parâmetros estabelecidos na lei. 


\begin{tabular}{|c|c|c|c|}
\hline Concorrência & \multicolumn{2}{|c|}{ Tomada de preços } & Concurso \\
\hline $\begin{array}{l}\text { Modalidade de licitação } \\
\text { entre quaisquer interes- } \\
\text { sados que, na fase inicial } \\
\text { de habilitação preliminar, } \\
\text { comprovem possuir os } \\
\text { requisitos mínimos de } \\
\text { qualificação exigidos no } \\
\text { edital para execução de } \\
\text { seu objeto. }\end{array}$ & \multicolumn{2}{|c|}{$\begin{array}{l}\text { Ocorre entre interessados } \\
\text { devidamente cadastrados } \\
\text { ou que atenderem a todas } \\
\text { as condições exigidas para } \\
\text { cadastramento até o } \\
\text { terceiro dia anterior à data } \\
\text { do recebimento das } \\
\text { propostas, observada a } \\
\text { necessária qualificação. }\end{array}$} & $\begin{array}{l}\text { Entre quaisquer interessados } \\
\text { para escolha de trabalho } \\
\text { técnico, científico ou } \\
\text { artístico, mediante a insti- } \\
\text { tuição de prêmios ou } \\
\text { remuneração aos vence- } \\
\text { dores, conforme critérios } \\
\text { constantes de edital publi- } \\
\text { cado na imprensa oficial } \\
\text { com antecedência mínima } \\
\text { de } 45 \text { dias. }\end{array}$ \\
\hline \multicolumn{2}{|l|}{ Convite } & \multicolumn{2}{|l|}{ Leilão } \\
\hline \multicolumn{2}{|c|}{$\begin{array}{l}\text { Para interessados do ramo } \\
\text { pertinente ao seu objeto, cadas- } \\
\text { trados ou não, escolhidos e } \\
\text { convidados em número mínimo } \\
\text { de } 3 \text { pela unidade administrativa, } \\
\text { a qual afixará, em local apro- } \\
\text { priado, cópia do instrumento } \\
\text { convocatório e o estenderá aos } \\
\text { demais cadastrados na corres- } \\
\text { pondente especialidade que } \\
\text { manifestarem seu interesse com } \\
\text { antecedência de até } 24 \text { horas da } \\
\text { apresentação das propostas. }\end{array}$} & \multicolumn{2}{|c|}{$\begin{array}{l}\text { Modalidade de licitação } \\
\text { entre quaisquer interessados } \\
\text { para a venda de bens móveis } \\
\text { inservíveis para a adminis- } \\
\text { tração ou de produtos } \\
\text { legalmente apreendidos } \\
\text { ou penhorados, ou para a } \\
\text { alienação de bens imóveis } \\
\text { prevista no art. 19, a quem } \\
\text { oferecer o maior lance, } \\
\text { igual ou superior ao valor } \\
\text { da avaliação. }\end{array}$} \\
\hline
\end{tabular}

Fonte: Lei 8.666/93, artigo 22 (BrasiL, 1993)

\section{Figura 1: Modalidades clássicas de licitação}

Com a finalidade inicial de ser utilizada exclusivamente pela União, foi criado recentemente o pregão, uma nova modalidade de licitação, posteriormente disciplinada pela Lei no 10.520 , de 17 de junho 2002. É com essa modalidade que se ocupa a próxima seção deste artigo.

\section{O pregão: nova modalidade de licitação}

Assim como as outras modalidades de licitação, o pregão se desenvolve por meio de vários atos da administração e dos licitantes, todos eles instituídos no processo respectivo. Compreende duas etapas, a primeira delas é a fase interna ou de preparação, e a seguinte, a fase externa. A fase interna do pregão, também chamada de fase preparatória pelo art. $3^{\circ}$ da Lei $\mathrm{n}^{\circ} 10.520$, desenvolve-se no âmbito interno do órgão ou da entidade responsável pela compra dos bens ou serviços desejados. Essa fase inicia-se com o ato da autoridade competente pelo qual justifica a necessidade da contratação, definindo seu objeto, as 
regras de habilitação, os critérios das propostas a serem aceitas, as sanções por inadimplemento e as cláusulas do contrato. (Meirelles, 2003).

A fase externa do pregão inicia-se com a convocação dos interessados. Nessa fase, encontra-se a maior vantagem do pregão em relação às outras modalidades de licitação, uma vez que estabelece a habilitação, ao final, apenas do licitante que ofertou o menor preço. Caso o licitante da oferta de menor preço não apresente os documentos conforme exigido no edital, será avaliada a proposta do segundo classificado e dos demais em ordem crescente. "Supri-se, assim, tempo precioso despendido no exame da documentação dos concorrentes que foram eliminados no julgamento das propostas" (Meirelles, 2003, p. 316).

Para essa modalidade, o tipo de licitação é sempre o de menor preço, observados ainda conforme o Decreto $3.555 / 2000$, art. $8^{\circ}$, “os prazos máximos para fornecimento, as especificações técnicas e os parâmetro mínimos de desempenho e de qualidade e as demais condições definidas no edital." Assim, as propostas escritas são dispostas em ordem decrescente de preços ofertados, sendo posteriormente oferecida a chance das melhores propostas abrirem os lances até o alcance do menor preço. Assim, ressalta Niebuhr: "No pregão, os licitantes mais bem classificados dispõem de uma segunda oportunidade, em que, de forma oral, podem reduzir os seus preços" (2004, p. 21). Vê-se que essa característica confere ao pregão a similaridade de um leilão às avessas, uma vez que são ofertados lances de forma oral e em voz alta até o alcance de proposta de menor preço.

De acordo com Gusmão (2004), as peculiaridades do pregão, destacadas na figura 2, são importantes porque instituíram uma modalidade de licitação com procedimento mais simplificado. Assim, vemos a importância da aplicabilidade do pregão à aquisição de bens e serviços comuns, uma vez que por outra modalidade demandaria mais tempo e maior custo.

\section{O pregão eletrônico}

O pregão como nova modalidade de licitação, foi instituído por meio da Medida Provisória n ${ }^{\circ} 2.026$, de 04 de maio de 2000, e regulamentado pelo Decreto $\mathrm{n}^{\circ} 3.555$, de 08 de agosto de 2000. Anteriormente, a Medida Provisória n ${ }^{\circ}$ 2.026/2000 instituía o pregão apenas no âmbito da União, conforme artigo $1^{\circ}$ "para aquisição de bens

- Aquisição de bens e serviços comuns: objetos simples, que não demandam especificações técnicas complexas.

- Apenas o fator preço é levado em consideração.

- Inversão das fases de licitação: habilitação depois das propostas julgadas.

- Há oportunidade para os licitantes melhor classificados reduzirem os seus preços.

Fonte: Niebuhr, 2004 e Gusmão, 2004. Com adaptações.

Figura 2: Peculiaridades do pregão 
e serviços comuns, a União poderá adotar licitação na modalidade pregão." Posteriormente, a Lei 10.520 , de 17 de julho 2002, estendeu a aplicação da modalidade pregão também aos estados e municípios.

A partir do Decreto n ${ }^{\circ} 5.450$, de 31 de maio de 2005, foi regulamentada a modalidade pregão, na forma eletrônica, de acordo com o dispositivo do art. $2^{\circ} \mathrm{da}$ Lei no 10.520 , destinada à aquisição de bens e contratação de serviços comuns.

O pregão eletrônico é a modalidade de licitação em que recursos de tecnologia de informação são utilizados para compra de bens e contratação de serviços comuns. Segundo Niebuhr, "em apertadíssima síntese, o pregão eletrônico é o modo de realizar a modalidade pregão, valendo-se da Internet" (2004, p. 226).

A particularidade desse meio de realização de compras incide na ausência física de quaisquer interessados ou documentos, já que os mesmos estão presentes via sistema eletrônico. Para a garantia da segurança do processo, temos a presença de recursos de criptografia e autenticação, que ajudarão na condução do sistema eletrônico. (Decreto no 5.450, art. $2^{\circ}$, \ $3^{\circ}$ ).

As atribuições da autoridade competente do órgão que promoverá o pregão eletrônico ${ }^{3}$ serão as mesmas do pregão comum, acrescentando-se apenas, a responsabilidade de indicar o provedor do sistema, "evitando que tal procedimento seja efetivado por outrem, mesmo que agente público”. (GuSMÃo, 2004, p. 73).

Gusmão (2004) explica que, ao pregoeiro caberão as mesmas responsabilidades atribuídas com a operação do pregão comum, deste se diferenciando por apresentar facilidades advindas do apoio do sistema de tecnologia. Para esse ponto, o autor declara:
Note-se que, nesse tocante o programa poderá em muito auxiliar e até aliviar o trabalho do pregoeiro, constando de sua rotina a exclusão automática de lances fora das condições de adminissibilidade da administração, como é o caso de lances iguais ou de valor reduzido, bem como recebendo ofertas e documentado-as, além de enviar mensagem ao licitante confirmando a operação (2004, p. 76)

Assim, percebe-se que existe uma vantagem do pregão eletrônico em comparação ao pregão comum, uma vez que há uma simplificação das atividades do pregoeiro já que o sistema recebe e ordena os lances automaticamente.

De acordo com o artigo $4^{\circ}$, do Decreto $\mathrm{n}^{\circ}$ 5.450, a modalidade pregão eletrônico será preferencial quando da aquisição de bens e serviços comuns realizada em decorrência de transferências voluntárias de recursos públicos da União. Aos outros casos de aquisição de bens ou contratação de serviços, deverão ser adotadas as outras modalidades ou, ainda, o pregão comum.

\section{Características do pregão na FUNASA/PB}

A FUNASA/PB é uma instituição do governo federal, órgão executivo do Ministério da Saúde, responsável em promover a inclusão social por meio de ações de saneamento e promoção e proteção à saúde dos povos indígenas. Por esse motivo, a gestão de compras é fundamental na coordenação entre o montante de recursos e a extrema carência do campo.

Para alcançar uma descrição das características da modalidade de licitação pregão na FUNASA/PB, nas formas eletrônica e presencial, aplicaram-se as 
seguintes técnicas de pesquisa: questionário composto de 35 questões, abertas e fechadas, entrevista e observação direta. O instrumento de coleta de dados foi aplicado entre os diferentes trabalhadores que interagem de alguma forma com o sistema de pregão na FUNASA/PB: agentes administrativos, assistentes administrativos e procurador federal. Os dados obtidos foram sujeitados a dois tipos de tratamento: qualitativo e quantitativo, concomitantemente. Tratou-se de um estudo exploratório para levantar questões a serem mais profundamente avaliadas.

Neste artigo divulgam-se alguns dos pontos considerados mais relevantes após a análise dos dados, ou seja, os que resultaram das questões referentes a: vantagens e desvantagens competitivas dos métodos de compras: pregão presencial e eletrônico; vantagens para o pregoeiro com o pregão eletrônico; disponibilidade de recursos hábeis para atendimento das despesas referentes ao planejamento anual $\mathrm{da}$ FUNASA/PB; economia de preço nos bens/serviços adquiridos por meio do pregão eletrônico, se comparada à do pregão presencial; economia de recursos com a introdução do pregão eletrônico e repasse de recursos para outras necessidades da FUNASA/PB; prazos de fornecimento dos bens/serviços adquiridos por meio do pregão presencial em comparação ao eletrônico, e treinamento e capacitação do pregoeiro e equipe.

\section{Análise e interpretação dos resultados \\ O pregoeiro e a equipe de apoio em exercício possuem treinamento e capacitação constantes (anual/semestral) para o exercício de suas funções?}

Com relação à questão, 60\% dos entrevistados responderam "raramente",
$20 \%$, "às vezes" e os outros $20 \%$ afirmaram que sempre o pregoeiro e a equipe de apoio possuem treinamento e capacitação para o exercício de suas funções.

De acordo com Decreto 3.555/2000, em seu art. $7^{\circ}$, "somente poderá atuar como pregoeiro o servidor que tenha realizado capacitação específica para exercer a atribuição", em nada se referindo quanto à periodicidade de treinamentos e capacitação do pregoeiro e da equipe de

"Percebe-se

uma vantagem do

pregão eletrônico

em relação ao

comum, uma vez

que bá simplificação

das atividades do

pregoeiro, já que

o sistema recebe e

ordena os lances

automaticamente."

apoio. Por outro lado, embora o citado decreto não se refira a freqüência de cursos para os envolvidos diretamente na condução do pregão, percebemos que a rara existência de treinamento e capacitação poderá abrir margens a falhas no desenvolvimento das etapas da licitação. Isso porque a reciclagem dos servidores a respeito da lei de licitações, bem como os procedimentos necessários a realização do 
pregão presencial e eletrônico, constitui-se como fator de importância a ser considerado pelos servidores para o exercício das suas funções.

Você acha que o material adquirido atende o órgão por tempo suficiente até uma nova aquisição?

Houve uma predominância das opiniões com relação "às vezes" que o material comprado atende o tempo suficiente até uma nova compra. Conforme observado na fundação, esse fator se deve a dois motivos: primeiro, a exemplo do exercício 2006, o orçamento da União por vezes demora a ser votado e, conseqüentemente, o repasse dos recursos não atende em tempo às necessidades da administração pública; outras vezes, no caso interno da fundação, há um descompasso entre a real necessidade e aquilo que se comprou efetivamente, levando tanto ao excesso quanto à falta de material. Esse motivo é conseqüência de um planejamento inadequado em consideração às necessidades internas da FUNASA/PB.

Em média, qual o percentual de utilização dos métodos pregão eletrônico e pregão presencial na Fundação Nacional de Saúde, da Paraíba?

Obteve-se como média das respostas o percentual de $92 \%$ para a utilização dos métodos pregão eletrônico e presencial na FUNASA/PB. Esse fator se deve à maior aquisição de bens e serviços comuns para atendimento das necessidades da fundação, adotando, dessa forma, o pregão como modalidade de licitação. Encontramos, também, obras e serviços realizados, em geral, por meio da modalidade tomada de preços, conforme limites de valor estabelecido na lei, que, por vezes, visa atender comunidades indígenas beneficiadas pela fundação.
Em geral, existe economia de preço com relação aos bens/serviços adquiridos por meio do pregão eletrônico quando comparado ao pregão presencial?

Houve predominância das opiniões que afirmaram existir economia de preço. Esse fator, conforme constatado, deve-se a um maior número de concorrentes que, por vezes, contribui para obtenção de menor preço para itens comprados para a FUNASA/PB. Dessa forma, percebemos a importância das compras realizadas com maior eficácia, pois assim há a possibilidade do uso de recursos remanescentes para outras atividades, trazendo benefícios consideráveis para a fundação.

Qual é, para você, a principal vantagem do pregão eletrônico em relação ao pregão presencial?

Do total, 67\% dos entrevistados responderam "maior número de licitantes", $22 \%$ "quebra de barreiras físicas entre pregoeiro e licitantes", e os outros 11\% afirmaram ser o desconto nos preços dos itens cotados a principal vantagem do pregão eletrônico em comparação ao pregão comum. Assim, mais uma vez, o pregão eletrônico na FUNASA/PB trouxe maior número de concorrentes, em virtude de propiciar encurtamento das distâncias aos possíveis interessados, auferindo, entre outras vantagens, obtenção de maiores descontos para os itens licitados.

Qual é, para você, a principal desvantagem do pregão eletrônico em relação ao pregão presencial?

Como resposta, 56\% dos entrevistados responderam "restrição de fornecedores que ainda não se utilizam da Internet", 33\%, "compra errada de bens/serviços", e os outros 11\% afirmaram ser a demora para entrega dos documentos originais a principal desvantagem do pregão eletrônico em relação ao pregão presencial. Conforme 
observado, durante o período de pesquisa, a restrição de fornecedores que ainda não se utilizam da Internet é verificada na necessidade de realização de pregão presencial em cidadezinhas localizadas no interior do estado. Tal fator se revela como custo de oportunidade, uma vez que há necessidade de deslocamento de servidor para o município em que se pretende realizar a licitação.

Para você, qual a principal vantagem para o pregoeiro com o pregão eletrônico?

Dos entrevistados, 55\% responderam "agilidade/simplificação na licitação em que há vários itens", 22\%, "exercício dos deveres em ambiente menos tumultuado (ou mais tranqüilo)", e os outros $22 \%$ afirmaram ser a simplificação dos deveres a principal vantagem para o pregoeiro com o pregão eletrônico, uma vez que o sistema recebe e ordena os lances. Dessa forma, percebemos que o pregão eletrônico propiciou para os servidores diretamente envolvidos no certame, uma redução do tempo gasto nas licitações em que há vários itens, simplificando também as disputas por lances, já que estes são recebidos e ordenados pelo sistema eletrônico. Por outro lado, devemos ressaltar que, com o pregão presencial o pregoeiro é sobrecarregado, já que ele é o condutor direto das etapas do certame, sendo responsável pelo recebimento dos envelopes, classificação dos licitantes, procedimento dos lances verbais, entre outros procedimentos, que por vezes tomam muito tempo até que seja finalizado todo o processo.

Na sua opinião, quais as situações em que é preferivel a utilização do pregão eletrônico em lugar do pregão presencial?

Houve uma predominância da licitação em que há vários itens, a exemplo de material de expediente, como situações em que é preferível a utilização do pregão eletrônico em lugar do pregão presencial. Encontramos, também, a assertiva de que em nenhuma situação o pregão comum é preferível em lugar do eletrônico, exceto quando existem situações em que os concorrentes não se utilizam da Internet para licitações. Dessa forma, enxergamos que a agilidade do sistema eletrônico em licitações com vários itens contribui para uma amenização das tarefas atribuídas às pessoas envolvidas na condução do pregão eletrônico na FUNASA/PB.

Assim, percebemos que servidores, direta ou indiretamente, envolvidos com o pregão eletrônico concordam ser essa modalidade o melhor instrumento para aquisição de bens/serviços. Ressalta-se que, durante o período de realização da pesquisa, foi observada a facilidade de procedimento da licitação quando realizada por meio do pregão eletrônico. Isso se deve, entre outros fatores, à ausência de lances verbais, que por vezes tornava o procedimento lento e complicado.

Opregão eletrônico estápossibilitando economia de recursos e possibilitando repasse desses para melhoria das diferentes necessidades presentes na FUNASA/PB?

Houve predominância de sempre haver economia de recursos e possibilidade do repasse desses para melhoria das necessidades presentes na FUNASA/ PB, mediante utilização do pregão eletrônico. Assim, a escassez de recursos disponíveis para bens/serviços considerados não tão importantes, delegados ao próximo exercício financeiro, foi parcialmente resolvida em fase da utilização de recursos provenientes da economia adquirida com a utilização do pregão eletrônico. 
Existe ou já existiu compra errada de bens/ serviços por meio da modalidade pregão eletrônico?

Para 57\% dos entrevistados, "às vezes"; 29\%, "raramente", e os outros $14 \%$ afirmaram que nunca existiu compra errada de bens/serviços por meio da modalidade pregão eletrônico. A existência de compra errada de bens/ serviços por meio da modalidade pregão se deve a dois fatores. Primeiramente, devido ao próprio caráter do pregão eletrônico,que não permite contato oral entre o pregoeiro e os licitantes para esclarecimentos que venham a ocorrer. Por outro lado, no caso interno da FUNASA/PB, temos que muitas vezes a real necessidade dos setores/divisões não é corretamente identificada, fator advindo de um planejamento inadequado que não visualiza as reais necessidades da referida fundação.

Qual é, pra você, a principal vantagem do pregão presencial em lugar do pregão eletrônico?

Do total, 56\% dos entrevistados responderam "possibilidade de exigir amostras dos produtos dos licitantes"; 33\%, "contato oral na fase de negociação", e os outros $11 \%$ afirmaram ser a representação de pequenos comerciantes, destituídos do sistema eletrônico (comprasnet). Segundo Niebuhr (2004), a exigência de amostras não deve ser regra, mas exceção a casos devidamente justificados. Ademais, a modalidade pregão, por se destinar à contratação de bens e serviços comuns, que não exigem análise detalhada, chega a ponto de requerer amostras. Assim, no caso da FUNASA/PB, considera-se relevante a exigência de amostra para licitações em que para a aquisição de bens/serviços seja importante conferir a qualidade e, conseqüente, a adequação do objeto licitado às necessidades administrativas.
Na sua opinião, quais as situações em que é preferivel a utilização do pregão presencial em lugar do pregão eletrônico?

Obtivemos como predominância das respostas ser preferível a utilização do pregão presencial em lugar do eletrônico quando o bem/serviço a ser licitado for fornecido em outra cidade que não seja João Pessoa. Conforme observado na FUNASA/PB, existem licitações que, a exemplo do fornecimento de combustíveis, o serviço a ser prestado dá-se em cidades do interior da Paraíba. Dessa forma, o pregão presencial com deslocamento do pregoeiro e equipe de apoio é o mais adequado, senão a única alternativa, já que, na maioria dos casos, os licitantes ainda não se utilizam da tecnologia de informação para venda de seus bens ou serviços.

Em sua opinião, qual a principal desvantagem do pregão presencial com relação ao pregão eletrônico?

Houve predomínio da restrição do número de participantes ser a principal desvantagem do pregão presencial com relação ao pregão eletrônico. No caso da FUNASA/PB, em licitações realizadas por meio da modalidade pregão presencial, a restrição de fornecedores se reflete na delimitação de bens/serviços ofertados e também no aumento de preços, ou total utilização do estimativo empenhado.

Os bens/serviços adquiridos pelo pregão presencial superam favoravelmente os prazos de fornecimento quando relacionados com o pregão eletrônico?

Para 25\% dos respondentes "sempre", e os outros 75\% afirmaram que às vezes os bens/serviços adquiridos pelo pregão presencial superam favoravelmente os prazos de fornecimento quando 
relacionados com o pregão eletrônico. Com a introdução do pregão eletrônico, vencedores localizados em regiões mais distantes atrasam o fornecimento. Entretanto, no caso da FUNASA/PB, esse não se revelou fator dominante na maioria das situações quando comparado ao pregão presencial. A razão é simples: mesmo em tal modalidade, geralmente vencida por fornecedor local, verificamse atrasos no fornecimento. Nesta modalidade, embora na maioria das vezes apresente como vencedor, fornecedor local, este também incide no descumprimento do prazo estabelecido para fornecimento.

A incidência de itens não cotados no pregão presencial em comparação ao pregão eletrônico é:

Afirmaram "menor" 14,4\%; "igual" $42,8 \%$, e $42,8 \%$ responderam ser "maior" a incidência de itens não cotados no pregão presencial em comparação ao pregão eletrônico. Quando maior a incidência de itens não cotados no pregão presencial, observamos a restrição do número de licitantes. Por outro lado, a igualdade da incidência de itens não cotados, tanto com o presencial quanto com o eletrônico, devese a especificidade ou escassez do bem ou serviço em dado momento no mercado, bem como a inconveniência da descrição de dado objeto no edital que, por vezes detalhada, torna inexistente a oferta de tal bem ou serviço a ser oferecido pelos interessados.

Dado o exposto, percebemos que a adoção da modalidade de licitação pregão eletrônico trouxe uma melhoria significativa nas atividades relacionadas à compra ou à aquisição de bens/serviços para atendimento das necessidades da FUNASA/PB, pois possibilitou economia de recursos e agilizou o processo interno de aquisição. Dessa forma, houve um benefício para o público alvo (povos indígenas) da FUNASA/PB. Como exemplo, podemos citar a compra de vacina, realizada em valores superiores a $\mathrm{R} \$$ 8.00,00 (oito mil reais) - pois em caso contrário demanda dispensa de licitação -, que passou a ser realizada por meio do pregão eletrônico ao invés do presencial, otimizando recursos por meio de mais presença de licitantes e um posterior

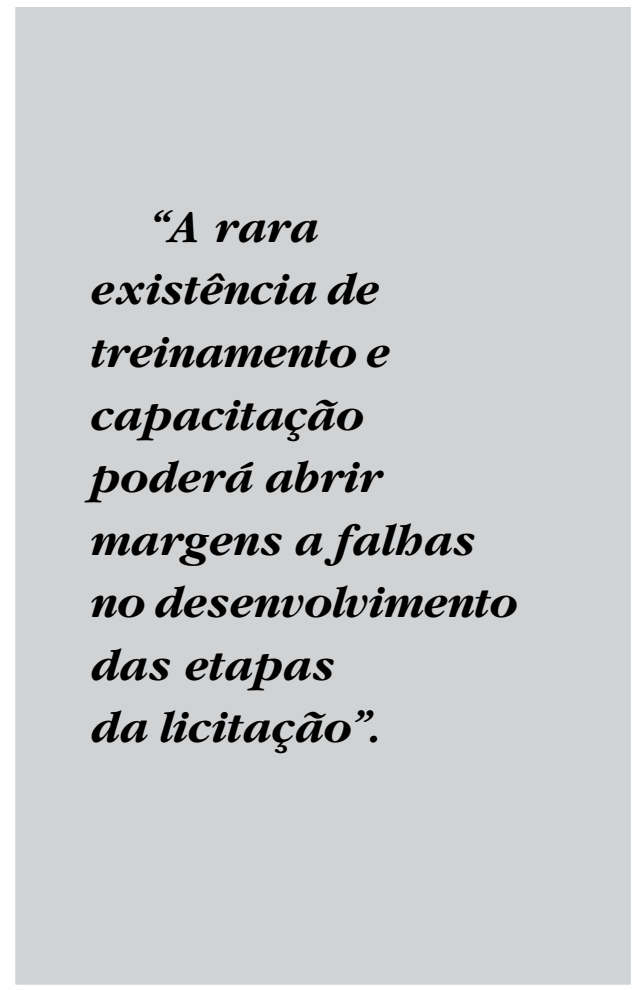

repasse desses para o atendimento de aquisições, algumas vezes delegadas ao próximo exercício financeiro. Constatamos também que referida modalidade é geralmente empregada para compra de bens/serviços de uso interno, ou seja, aqueles considerados comuns, que podem ser descritos objetivamente por meio de especificações usuais de mercado. Assim, a aquisição de bens, a exemplo de material 
de expediente e aparelhos eletro/eletrônicos, bem como de serviços referentes a contrato de limpeza ou de vigilância, foram contempladas por meio da introdução do pregão eletrônico. Por outro lado, para serviços mais complexos, a exemplo de contrato de obras para construção de poços que beneficiam diretamente ao público alvo da FUNASA/PB, continuaram a ser utilizadas outras modalidades de licitação, tais como tomada de preços.

\section{Comparação entre os métodos de compra: pregão presencial e eletrônico}

Cada um dos métodos descritos objetiva adequar a administração pública aos preceitos da Lei Federal no 8.666, que estabelece normas gerais sobre licitações e contratos administrativos, oferecendo suporte ao funcionamento eficiente e perfeitamente regulamentado da compra ou da aquisição de bens e serviços. (art. $1^{\circ}$ ). Embora apresentem o mesmo princípio, os métodos de compra pregão presencial e eletrônico se distinguem na maneira como resultam vantagens e desvantagens para o órgão publico em que são utilizados. Torna-se, portanto, relevante considerar as principais particularidades de cada um desses métodos no que se refere ao alcance de resultados para a FUNASA/PB.

Para o método de compra pregão comum, obtivemos como vantagem principal, em relação ao eletrônico, a possibilidade de exigência de amostras de produtos dos licitantes. Esse fator foi considerado importante para conferência de qualidade, uma vez que possibilita o exame do objeto a ser adquirido, possibilitando ainda o contato oral para esclarecimento de quaisquer dúvidas. Por outro lado, a principal desvantagem verificada foi a restrição do número de participantes, já que nem todos os fornecedores se utilizam do meio eletrônico para venda de seus bens/ serviços. Essa limitação trouxe como conseqüência situações em que é preferível, senão a única alternativa, a utilização do pregão comum à do pregão eletrônico, a exemplo de licitações para aquisições de bens/serviços comuns em cidades do interior do estado.

Por sua vez, o pregão eletrônico apresentou como principal vantagem o maior número de licitantes, que foi propiciada pelo encurtamento das distâncias aos possíveis interessados. Segundo Niebuhr, "a principal vantagem dos recursos de tecnologia de informação é a aproximação das pessoas, o encurtamento das distâncias." (2004, p. 229). Como principal desvantagem, a presença de fornecedores que ainda não se utilizam da Internet foi considerada relevante; como exemplo, citamos as licitações que são realizadas em regiões onde os fornecedores, seja por desconhecimento ou falta de tecnologia adequada, não se servem de meios eletrônicos para venda de seus bens/serviços. Outra vantagem constatada foi a economia de preço, que possivelmente são repassados para atendimento de outras necessidades da fundação. Destaca-se, ainda, a vantagem para o pregoeiro com a introdução do pregão eletrônico, uma vez que os procedimentos administrativos foram agilizados e simplificados, facilitando, principalmente, aquelas licitações em que vários itens são cotados. Fatores como esses fizeram prevalecer a preferência do pregão eletrônico ao comum, uma vez que para compras de muitos bens/serviços, o sistema eletrônico contribui simplificando o processo administrativo. 
Pode-se, então, com base nas particularidades de cada método, estabelecer algumas diferenças significativas. Por outro lado, verificamos que cada um deles, a seu modelo, é adequado a mesma situação: aquisição de bens/serviços comuns. Apesar disso, não se conjugam quanto à combinação ou justaposição de seus procedimentos, uma vez que um é realizado com a presença de licitantes, e o outro, com total ausência dos seus interessados.

\section{Reflexão resultante da compa- ração entre os métodos de compra: pregão presencial e eletrônico.}

A apreciação do presente estudo permite compreender como a aquisição de bens/serviços comuns pode trazer diferentes benefícios à administração pública. Considerando que a Lei 8.666/ 1993 não admite combinação das modalidades de licitação, ainda que tenha como finalidade o melhor atendimento ao interesse público, torna-se obrigatória a escolha de um único modelo para satisfação das necessidades ora requeridas.

Conforme indica o cotejo ora realizado, o pregão eletrônico reúne todas as características que trazem maiores vantagens à administração pública. Essa modalidade, além de simplificar todo o procedimento administrativo, alcança índices consideráveis de economia de recursos em virtude de poder alcançar grande parte do território nacional por meio do uso da Internet. Assim, constatase uma evolução no que se refere à compra de bens/serviços comuns, que a partir da introdução do pregão eletrônico vem proporcionando cumprimento mais moderno e eficiente para utilização eficaz dos recursos públicos.

\section{À guisa de conclusão}

A gestão de processos organizacionais é um entrelaçar permanente de fluxos de informação orientados por conteúdos estruturais, sistêmicos e da própria cultura interna das organizações. No serviço público, onde fatores peculiares e distintos daqueles mais usualmente prescritos pelo management contam muito na análise de qualquer questão, a complexidade das ações gerenciais é ainda mais aguçada. Principalmente, por esse motivo, um estudo preliminar como este apenas mostra pontas de icebergs no horizonte. Qualquer necessidade de intervenção em processos como o aqui descrito tem infinitamente mais fatores e informação especializada a considerar do que apenas essas poucas considerações iniciais apresentadas. Contudo, cumprindo o papel de mostrar alguns fatores para a investigação posterior, com mais propriedade, da sua constituição subjacente, a pesquisa realizada leva a destacar alguns pontos.

Primeiro, cabe dizer que como pontos fortes na gestão de compras com a prática do pregão no órgão federal estudado destacam-se: a economia de recursos propiciada pela utilização principalmente do pregão eletrônico e o repasse desses recursos para melhorias de diferentes necessidades da instituição; otimização do processo de aquisição de bens/serviços, permitindo um maior número de participantes e redução dos preços; agilidade/ simplificação na licitação realizada por meio do pregão eletrônico. Paralelamente, a presença de treinamento e capacitação, ainda não suficientemente observados, parece ser uma ameaça à eficácia do sistema vigente. Soma-se a esse fator o problema de planejamento anual mal dimensionado que se apresenta como uma outra deficiência a ser avaliada. 
A partir dessas considerações, sugeremse dois pontos a serem estudados: a elaboração e a implantação política de capacitação para os servidores envolvidos na condução da modalidade de licitação pregão; a análise de sistemas de auditoria do processo de planejamento anual, visando à identificação de mecanismos de ajuste do volume estimado do fluxo de bens e serviços da FUNASA/PB para possibilitar ações de correção em tempo hábil.

(Artigo recebido em janeiro de 2007. Versão final em junho de 2007)

\section{Notas}

1 Sociedade de economia mista, empresas públicas e outras controladas direta e indiretamente pelo poder público

2 OS: Organizações Sociais; OSCIP: Organizações Sociais de Interesse Público

$3 \mathrm{O}$ artigo $8^{\circ}$ do Decreto ${ }^{\circ} 5.450$ dispõe sobre as atribuições da autoridade competente do órgão que promoverá o pregão eletrônico.

\section{Referências bibliográficas}

Alexandrino, Marcelo; Paulo, Vicente. Direito administrativo. Rio de Janeiro: Impetus, 2006.

Azevedo, Eurico de Andrade; Alencar, Maria Lucia Mazzei de. Concessão de Serviços Públicos - comentários às Leis 8.897 e 9074 (parte geral), com as modificações introduzidas pela Lei 9.648, de 27-5-98. São Paulo: Malheiros, 1998.

Brasil. Medida Provisória no 2.026-3, de 4 de maio de 2000. Institui no âmbito da União, nos termos do art. 37, inciso XXI, da Constituição Federal, modalidade de licitação denominada pregão, para aquisição de bens e serviços comuns.

. Decreto $n^{\circ} 3.555$, de 8 de agosto de 2000 . Aprova o regulamento para a modalidade de licitação denominada pregão, para aquisição de bens e serviços comuns. . Decreto $n^{0} 5.450$, de 31 de maio de 2005. Regulamenta o pregão, na forma eletrônica, para aquisição de bens e serviços comuns, e da outras providências.

- Decreto $n^{\circ}$ 5.504, de 05 de agosto de 2005. Estabelece a exigência de utilização do pregão, preferencialmente na forma eletrônica, para entes públicos ou privados nas contratações de bens e serviços comuns, realizadas em decorrência de transferências voluntárias de recursos públicos da União, decorrentes de convênios ou instrumentos congêneres, ou consórcios públicos. 
Lei $n^{\circ}$ 10.520, de 17 de julho de 2002. Institui, no âmbito da União, Estados, Distrito Federal e Municípios, nos termos do art.37, inciso XXI da Constituição Federal, modalidade de licitação denominada pregão, para aquisição de bens e serviços comuns, e da outras providências.

. Lei no 8.666, de 21 de junho de 1993. Dispõe sobre Licitações e Contratos de Administração Publica. Regulamenta o artigo 37, inciso XXI, da Constituição Federal, institui normas para licitações e contratos da Administração Pública e da outras providências.

BRitTo, Carlos Ayres. O perfil constitucional da licitação. Paraná: Znt, 1997.

Cavalcante, Jacqueline Nunes. A aquisição de bens/serviços por meio de licitação na modalidade pregão presencial e eletrônico na Fundação Nacional de Saúde da Paraíba. João Pessoa: UFPB, 2006.

Dias, Marcos Aurélio P. Administração de materiais: uma abordagem logística. $4^{\circ}$ ed. São Paulo: Atlas, 1995.

Di Pietro, Maria Sylvia Zanella. Direito administrativo. $17^{\circ}$ ed. São Paulo: Altas, 2004.

FARIA, Edimur Ferreira de. Curso de direito administrativo positivo. $4^{\circ} \mathrm{ed}$. Belo Horizonte: Del Rey, 2001.

Gusmão, Joseneide Helena de Castro. Pregão: nova modalidade de licitação. João Pessoa: UFPB, 2004.

Heinritz, Stuart F.; Farrell, Paul V. Compras: princípios e aplicações. São Paulo: Atlas, 1972.

JúnIor, Waldo Fazzio. Fundamentos do direito administrativo. $2^{\circ}$ ed. São Paulo: Atlas, 2002.

Lakatos, Eva Maria; Marconi, Marina de Andrade. Metodologia do trabalho científico. São Paulo: Atlas, 1996.

Lima, Marília Coelho Gondim de Oliveira. Licitação-ferramenta de compras no setor público: contratação direta e pregão. João Pessoa: UFPB, 2004.

MAGEE, John F. Logística industrial: análise e administração dos sistemas de suprimento e distribuição. São Paulo: Pioneira, 1977.

Meirelles, Hely Lopes. Direito administrativo brasileiro. 28 ed. São Paulo: Malheiros, 2003.

MotтA, Carlos Pinto Coelho. Pregão: teoria e prática: nova e antiga idéia em licitação pública. São Paulo: NDJ, 2001.

Niebuhr, Joel de Menezes. Pregão presencial e eletrônico. Curitiba: Zênite, 2004. 


\section{Resumo-Resumen-Abstract}

\section{Vantagens e desvantagens do pregão na gestão de compras no setor público: o caso da} Funasa/PB

Jacqueline Nunes; Rosivaldo de Lima Lucena e Orlando Gomes da Silva

O presente artigo é parte de um estudo exploratório cujo objetivo foi analisar as vantagens e desvantagens na aquisição de bens e serviços por meio das modalidades de licitação pregão presencial e eletrônico no serviço público. Para isso, foi realizado um estudo de caso na Fundação Nacional de Saúde da Paraíba. A parte da pesquisa divulgada neste artigo, além de uma síntese sobre o referencial teórico, apresenta as características investigadas da modalidade de licitação pregão, comparando suas formas presencial e eletrônica na instituição estudada. Os resultados apontam aspectos relevantes quanto às questões: vantagens e desvantagens do pregão eletrônico em relação ao pregão presencial e vice-versa; recursos para atendimento de despesas; planejamento anual da FUNASA/PB; economia de preço; economia e repasse de recursos para outras necessidades; prazos de fornecimento; treinamento e capacitação de pessoal. Conclui a exposição destacando alguns pontos fortes e fracos do processo, sugerindo medidas a serem avaliadas no que tange a capacitação de pessoal e planejamento anual na FUNASA/PB.

Palavras-chave: pregão; pregão eletrônico; gestão pública; eficácia.

\section{Ventajas e desventajas del subasta revestida na gestión de compras en el sector publico- el caso del FUNASA/PB}

Jacqueline Nunes; Rosivaldo de Lima Lucena y Orlando Gomes da Silva

El actual artículo es parte de un estudio exploratório cuyo objetivo es analizar las ventajas y las desventajas en la adquisición de bienes y servicios por medio de la modalidad de licitación: subasta presencial o electrónica ,en el servicio público. Para esto, un estudio de caso en la fundación nacional de la salud del Paraíba fue llevado a cabo. La parte de la investigación divulgada en este artículo, más allá de una síntesis sobre el referencial teórico, presenta las características investigadas de la modalidad de licitación, comparando sus formas presencial y electrónica en la institución estudiada. Los resultados señalan aspectos importantes en las cuestiones de ventajas y desventajas de la subasta electrónica en lo referente a la presencial y viceversa; recursos para la atención de gastos; planeamiento anual del FUNASA/PB; economía de precio; economía y repases de los recursos para otras necesidades; plazos de provisión; entrenamiento y calificación de personal. Uno concluye poniendo en evidencia puntos fuertes y débiles del proceso y haciendo sugerencias de medidas que deberán ser evaluadas en lo que se refiere a la calificación de personal y al planeamiento anual en la FUNASA/PB.

Palabras-clave: proclamación; subasta a la baja administración pública; eficacia.

\section{The advantages and disadvantages in reverse auction: the case of FUNASA/PB Jacqueline Nunes; Rosivaldo de Lima Lucena and Orlando Gomes da Silva}

This article is part of an exploratory study whose objective was to evaluate conventional and reverse auction trade-offs in the public service. To achieve that goal, a case study was accomplished at the National Health Care Foundation in Paraíba State, Brazil (Fundação Nacional de Saúde da Paraíba-FUNASA/PB). Besides a summary about theoretical references, the excerpt of the research published in this article presents the investigated characteristics concerning procurement bidding, comparing its conventional and electronic approaches in the institution under study. The results show relevant aspects of the following subjects: conventional and reverse auction trade-offs; resources for expenditure; annual planning of FUNASA/PB; price economy; economy and resource transfers 
to other needs; provisions timing and staff training. The conclusion emphasizes both positive and negative points concerning the process, and suggests that actions must be evaluated during staff training and annual planning at FUNASA/PB.

Keywords: reverse auction, e-reverse auction; public management; efficacy.

Jacqueline Nunes

Graduada em Administração. Contato: <jack.nunes@gmail.com>.

Rosivaldo de Lima Lucena

Graduado em Administração, Mestre e Doutorando em Engenharia de Produção. Atualmente é professor do Departamento de Administração da UFPB. Contato: <rosivaldo.lucena@uol.com.br>.

Orlando Gomes da Silva

Graduado em Administração, Mestre em Engenharia de Produção, Professor do Instituto de Educação Superior da Paraíba. Contato: <orlandosilva@gmail.com>. 